\title{
Von recklinghausen's disease and emphysema case
}

\section{report}

Keywords: Pulmonary arterial hypertension, Lung disease, Neurofibromatosis, Multipleneurofibromas, Emphysema

\section{Case report}

Female of 59 years old, exposed to biomass smoke (index $=100 \mathrm{hrs/}$ year), followed as Chronic Obstructive Lung Disease during 9 years; her main symptom has been dyspnea, vital signs HR 86 per min, RR 20 per $\mathrm{min}, 110 / 78 \mathrm{mmHg}$, body temperature $36.6^{\circ} \mathrm{C}$, very severe obstruction in spirometry, low Diffusion Capacity, increased Residual Volume, Pulmonary Arterial hypertension by echocardiography (47 $\mathrm{mmHg}$ ) and arterial gases $\mathrm{pH} 7.38, \mathrm{PaCO}_{2}=47 \mathrm{mmHg}, \mathrm{PaO}_{2} 66$ $\mathrm{mmHg}, \mathrm{HCO}_{3}=21.6$ and $\mathrm{O}_{2}$ saturation $92.5 \%$ with oxygen supply. Radiographic studies Figure 1 showed, bullous emphysema at left lung in conventional chest radiography; and, neurofibromatosis lesions in both hands (Figure 2) and feet (Figure 3) and Computed tomography revealing bilateral emphysema and bullae (Figure 4).

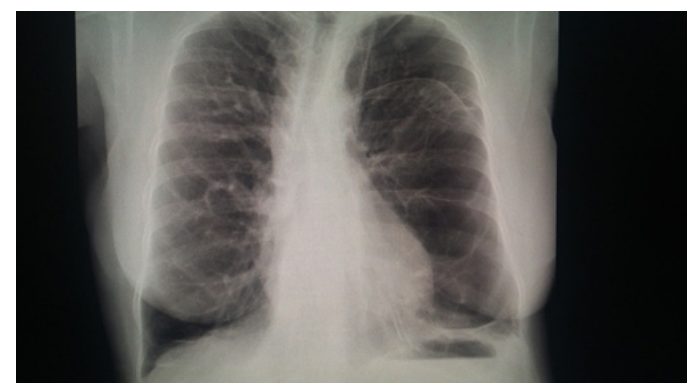

Figure I Chest $X$ ray.
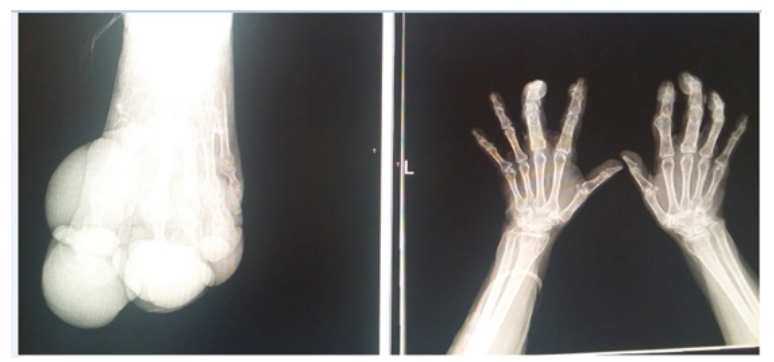

Figure 2 Neurofibromatosis Lesions.

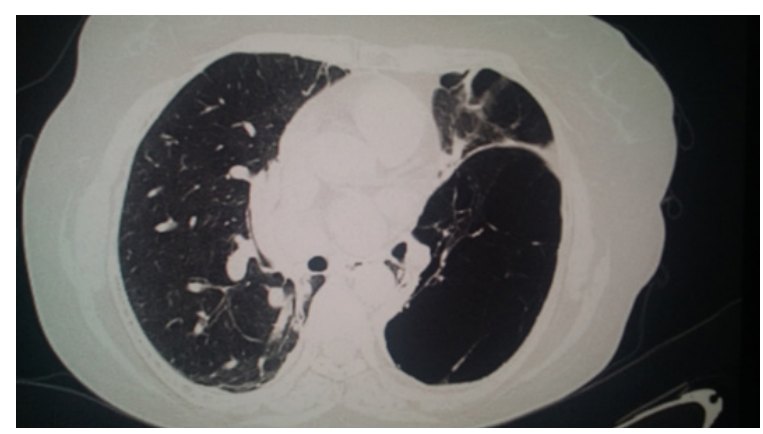

Figure 3 Bullous emphysema I.

\author{
Volume 4 Issue 3 - 2017
}

Hernandez-Zenteno R, Velazquez-Montero A, Flores Trujillo F, Espinosa de los Monteros C National Institute of Respiratory Diseases, COPD Clinic, Mexico

Correspondence: Hernandez-Zenteno R, National Institute of Respiratory Diseases, COPD Clinic, Mexico City, Mexico, Email rafherzen@yahoo.com.mx

Received: January 01, 2017 | Published: July 19, 2017

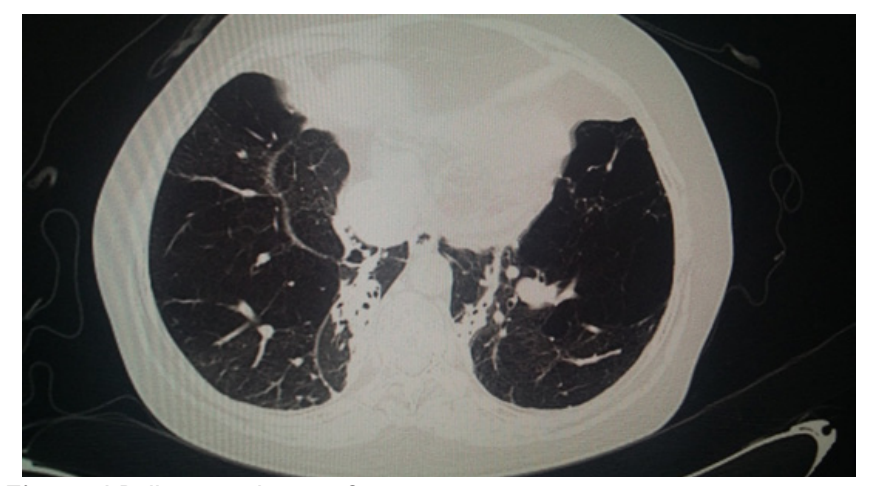

Figure 4 Bullous emphysema 2.

\section{Review}

Von Recklinghausen's disease or neurofibromatosis type 1 and 2 (NF1-2), is a common autosomal disorder characterized by multipleneurofibromas, cafe au lait spots, and Lisch nodules of theiris with a variable clinical systemic expression. Its prevalence estimated to be 1 in 3,000 live births, and males outnumbered females. ${ }^{1}$ Respiratory manifestations and Lung involvement in NFis a wellknown complication, in only $5 \%$ of cases; the most reported symptom is dyspnea and the alterations consists of chest wall deformities, upper airway obstruction by neurofibromatosis, primary pulmonary hypertension, central hypoventilation, diaphragm paralysis, diffuse interstitial fibrosis and bullae, eitheralone or in combination. Estimated incidences of findings are for interstitial fibrosis 7-50\%, bulla $18-50 \%$, ground-glass opacities $9-37 \%$, nodules $9 \%$, cysts $14-$ $25 \%$ and for mediastinal masses $14 \% .^{2-5}$

Smoking histories are documented in $25 \%$ of patients, but its association with NF remains controversial and unclear. In nonsmoking NF occasionally a minimal micro nodular pattern of ground glass opacity is observed and less common emphysema, fibrosis, honecombing or severe bullous disease and may be entirely asymptomatic., ${ }^{2,3}$ Our particular case was exposed to significant biomass smoke, which do not have association with bullous emphysema as tobacco smoking does. 


\section{Acknowledgment}

None.

\section{Conflict of interest}

None.

\section{References}

1. Shen MH, Harper PS, Upadhyaya M. Molecular genetics of neurofibromatosis type 1 (NF1). J Med Genet. 1996;33(1):2-17.

2. Lovin S, Veale D. Respiratory manifestations in von Recklinghausen's disease. Pneumologia. 2005;54(4):186-190.
3. Zamora AC, Collard HR, Wolters PJ, et al. Neurofibromatosisassociated lung disease: a case series and literature review. Eur Respir J. 2007;29(1):210-214.

4. Oikonomou A, Vadikolias K, Birbilis T, et al. HRCT findings in the lungs of non-smokers with neurofibromatosis. Eur J Radiol. 2011;80(3):e520e523.

5. Ueda K, Honda O, Satoh Y, et al. Computed tomography (CT) findings in 88 neurofibromatosis 1 (NF1) patients: Prevalence rates and correlations of thoracic findings. Eur J Radiol. 2015;4(6):1191-1195. 